RU Конфликтная ситуация в переводческом аспекте (на примере перевода англоязычных и русскоязычных конфликтем, основанных на оценочности)

\author{
Дедюхина А. С., Иванова С. А., Шагеева А. А.
}

Аннотация. Цель проводимого исследования - выявить способы передачи конфликтных ситуаций при переводе с английского языка на русский и с русского языка на английский. Конфликтные ситуации вербализуются через конфликтемы. Оценочность обозначенной конфликтогенной языковой единицы рассматривается как неотъемлемый компонент вербализации конфликтной ситуации, обусловливающий векторность ее разрешения. Научная новизна данной работы заключается в попытке анализа вербализации конфликтной ситуации через категорию оценочности в переводческом аспекте. В результате выявлены и описаны способы и приемы передачи конфликтных ситуаций в переводе, а также необходимые для этого переводческие стратегии.

\title{
EN Conflict Situation in Translation Aspect (by the Example of the Translation of English-Language and Russian-Language Conflictogenic Words Based on Evaluative Connotation)
}

\author{
Dediukhina A. S., Ivanova S. A., Shageeva A. A.
}

\begin{abstract}
The aim of the work is to find out the ways of rendering conflict situations in interpreting and translating from English into Russian and vice versa. Conflict situations are verbalized through conflictogenic words/units. Evaluation connotation of conflictogenic units is considered to be an integral part of verbalization of a conflict situation, which determines its development. Analysis of a conflict situation verbalization via the category of evaluation in the translation aspect is the novelty of the current study. As a result, we found and described the means to deal with conflict situations in interpreting/translating, as well as related strategies.
\end{abstract}

\section{Введение}

Одной из компетенций, необходимых переводчику для успешного осуществления профессиональной деятельности, выступает конфликтологическая компетентность, которая заключается в умении разбираться во взаимоотношениях людей, умении улаживать разногласия между ними, примиряя межкультурные противоречия для организации дальнейшего сотрудничества общающихся (Киндеркнехт, 2019, с. 153).

Ввиду этого важным представляется регулярное обращение с позиции верификации существующих теоретических положений по данному вопросу к опыту переводчиков при выполнении ими профессиональных задач в условиях конфликтогенности межкультурной коммуникации в динамично меняющемся современном мире. Актуальность исследования обусловлена необходимостью междисциплинарного комплексного научного анализа реализованных переводческих решений, проводимого на стыке конфликтологии и лингвистики, что может способствовать совершенствованию механизмов вербального разрешения конфликтных ситуаций в переводе. В этой связи через призму переводческого аспекта нами рассматривается конфликтная ситуация и ее вербализация посредством конфликтогенных единиц с выраженным оценочным компонентом.

Материалом исследования послужили видеозаписи и стенограммы международных пресс-конференций и переговоров с участием политических деятелей в период с 2018 по 2020 гг.

В соответствии с заявленной темой мы поставили перед собой следующие задачи: во-первых, определить ключевые понятия исследования; во-вторых, проанализировать актуальные примеры решения переводческих 
задач передачи конфликтных ситуаций в устном переводе и выявить переводческие стратегии, необходимые для их эффективного разрешения; в-третьих, описать переводческие приемы, используемые в зависимости от избранной речеповеденческой стратегии в английском и русском языках как языках перевода.

Для решения данных задач мы воспользовались такими общенаучными и собственно лингвистическими методами, как метод анализа текста, методы сравнения и описания, метод сплошной выборки, метод компонентного анализа, коммуникативно-прагматический метод, контекстологический метод.

Решение обозначенных задач стало возможным благодаря теоретической базе, представленной трудами, которые раскрывают понятие конфликтемы и оценочности (Жельвис, 2001; Иванова, 2012; Осипова, 2011) и посвящены описанию переводческих стратегий поведения в конфликтных ситуациях (Алексеева, 2004; Виноградова, 2013; Миньяр-Белоручев, 1986; Третьякова, 2000).

Практическая значимость исследования заключается в возможности использовать результаты работы в практической деятельности переводчика для решения переводческих задач передачи конфликтных ситуаций в устном переводе, а также в процессе преподавания следующих университетских дисциплин: стилистика, теория и практика перевода.

\section{Основная часть}

Для того чтобы переводчик эффективно решил профессиональную задачу, связанную с передачей конфликтной ситуации при переводе, он должен понимать, в чем она заключается, как реализуется в языке, какую переводческую стратегию выбрать и какими языковыми и речевыми средствами воспользоваться согласно выбранной стратегии. Этой стороне переводческой деятельности посвящен ряд работ, в которых говорится о необходимости со стороны переводчика быть готовым разрешить конфликтную ситуацию. В частности, Р. К. Миньяр-Белоручев (1986, с. 56) отмечает функцию фильтрации и адаптации текста, когда переводчик может изменить содержание и эмоциональную окраску сообщения под влиянием факторов экстремальности. Или в главе об этике переводчика учебного пособия «Введение в переводоведение» находим: «В некоторых случаях в обстановке устного последовательного или синхронного перевода переводчик оказывается лицом, облеченным также и дипломатическими полномочиями (например, при переводе высказываний крупных политиков в обстановке международных контактов). Если эти дипломатические полномочия за переводчиком признаны, он имеет право погрешить против точности исходного текста, выполняя функцию вспомогательного лица в поддержке дипломатических отношений, препятствуя их осложнению, но не обязан защищать при этом интересы какой-то одной стороны» (Алексеева, 2004, с. 30).

Тем не менее, вопрос о том, всегда ли переводчик должен сглаживать конфликт или сохранять конфликтность высказываний, остается открытым. Рассматривая описанные в научной литературе переводческие стратегии, мы можем привести слова Е. В. Виноградовой (2013, с. 32), которая писала, что переводчик принимает стратегию либо сотрудничества, либо конфронтации вслед за участниками переговоров.

За экспертным мнением мы обратились к 10 практикующим переводчикам, специализирующимся на устном и письменном переводе в трудных условиях, к которым также можно отнести и конфликтные ситуации, причинами которых становятся, например, халатное отношение к срокам поставок или выполнения работ, некомпетентность и низкое качество производства, экстренные случаи. Получив комментарии переводчиков на этот счет, мы выявили, что даже если стороны или одна сторона выбирают стратегию конфронтации, то чаще всего переводчики пытаются обратить ее в сотрудничество, выступая в функции так называемого «буфера», сдерживающего эмоциональную составляющую конфликта. Так, только трое из опрошенных переводчиков считают, что нужно переводить точно, ничего не смягчая. Остальные специалисты пытаются вернуть конфликтную ситуацию в более продуктивное русло, опуская инвективы, используя эвфемизмы или перефразируя в общих чертах высказывания конфликтующих сторон. Тем не менее, следует отметить, что обсценную лексику опускают практически все переводчики, даже если сами претензии передаются в полном объеме. Считаем важным тот факт, что большинство переводчиков (7 из 10 специалистов, принявших участие в обсуждении) говорили об эффективности и положительных результатах своей стратегии поведения в конфликте, которая могла быть как конфронтацией вслед за стороной переговоров, так и сотрудничеством.

Воспринимать ли конфликт как разрушающий или, наоборот, созидающий, очевидно, зависит от каждой конкретной ситуации. Однако неоспоримым видится тот факт, что для адекватного перевода в конфликтной ситуации важна лингвистическая компетентность переводчика: грамотность, умение использовать языковые средства в соответствии с целями и обстановкой общения, поскольку конфликт может возникнуть только на базе коммуникативного контакта: противоположность мнений, не выраженная эксплицитно, не может считаться конфликтом (Третьякова, 2000, с. 127). В таком случае язык и речь коммуникантов как субъектов конфликта становятся основополагающими факторами развития конфликтной ситуации, то есть сама конфликтная ситуация получает вербальное выражение и развитие.

В связи с этим возникает необходимость введения в исследование такого понятия, как «конфликтема», т.е. конфликтная единица на языковом уровне. Т. Н. Иванова (2012, с. 238) определяет конфликтемы как единицы прагматического уровня, ведущим признаком которых является векторность (примирительный/ наступательный вектор поведения участника конфликта) и способность провоцировать или эскалировать конфликт в определенных условиях. Еще одно определение конфликтем предлагает А. А. Осипова (2011, с. 81): языковые средства, провоцирующие конфликт (то, что актуализирует конфликтный сценарий развития дискурса). 
Наиболее распространенными представляются лексические конфликтемы (лексемы с негативным семантическим значением, как денотативным, так и коннотативным; лексемы, принадлежащие другому функциональному стилю и т.д.). Частным и крайним случаем лексических конфликтем служат инвективы лексемы, принадлежащие некодифицированному или табуированному разделу общенационального словаря (Жельвис, 2001, с. 11). На синтаксическом уровне можно выделить такие конфликтемы, как риторические вопросы, параллельные синтаксические конструкции и т.д. Фонетическими конфликтемами могут выступать намеренные отклонения от норм орфоэпии, диалектное произношение, а также просодические особенности речи. Отметим, что для реализации языкового средства в качестве конфликтемы важна соответствующая интенция говорящего (угроза, упрек, обвинение, долженствование и т.д.), однако интенция слушающего также может повлиять на конфликтогенность языковой единицы, что подтверждает наличие прагматического компонента конфликтем.

В данном исследовании мы не предпринимаем попытку осветить все многообразие конфликтем, а сосредоточимся только на оценочном компоненте конфликтем и, соответственно, рассмотрим оценочность как один из способов создания конфликтной ситуации, который, впрочем, может реализовываться на всех уровнях языка. Под оценочностью будем понимать «суждение говорящего, его отношение - одобрение или неодобрение, желание, поощрение и т.п. - как одну из основных частей стилистической коннотации» (Нелюбин, 2003, с. 134). И. В. Арнольд (2002, с. 81) выделяет только два генерализированных качества оценочности: одобрение (положительное суждение) и неодобрение (отрицательное суждение). Отрицательная оценка, очевидно, может составлять основу конфликтем. Следует отметить, что оценочность - неотъемлемое звено политической коммуникации, поэтому для анализа роли оценки в создании коммуникативного конфликта мы обратились к записям пресс-конференций и публичных выступлений на международных площадках (Генеральная Ассамблея ООН, Совет Безопасности ООН, конференция стран ОПЕК и т.д.), в которых принимали участие высокопоставленные политические деятели России, а также к политическим речам кандидатов в президенты США: Д. Трампа и Дж. Байдена. Языковой материал представлен двумя языками - русским и английским. Временные рамки выборки составляют 2018-2020 годы. При рассмотрении материала мы обращали внимание на потенциально конфликтогенные ситуации на международной арене: сокращение ядерного потенциала, выход США из Совместного всеобъемлющего плана действий, соглашение о сокращении добычи нефти, территориальный вопрос на Ближнем Востоке, предвыборная гонка и т.д. Анализу подвергался также перевод указанных выступлений на русский или английский языки соответственно. Перевод предоставлялся в открытом доступе аккредитованными СМИ, официальными каналами Министерства иностранных дел Российской Федерации и Белого дома.

Анализ практического материала показал, что, несмотря на популярное мнение о сглаживании конфликта как одной из задач переводчика, эта переводческая стратегия реализовывалась нечасто. К ней прибегали, когда негативная оценка достигала высокого «градуса». Например: Руководство... не будет озираться на русофобов, которых сейчас там пытается опять, по-моему, прежний президент поднимать на борьбу уже с режимом в Тбилиси (Выступление и ответы..., 2019). Как видно, в данном отрывке используется слово «русофоб» с отрицательной семантикой, вербализующее негативную оценочность. При переводе данного отрывка было использовано опущение, за счет чего произошла нейтрализация негативной оценки: The authorities... will not be proceeding from the action, the problems that the new president is trying to use again (Организация Объединенных Наций, 2019). В следующем примере также приемы генерализации и опущения сглаживают конфликтность за счет смягчения степени неодобрения: Но то, что он произошел впервые за многие-многие годы, что он сидит в тюрьме по голословному обвинению, по подложному делу, это, конечно, нас не радует (Выступление и ответы..., 2019). / But the fact that it happened over numerous years that he spent in prison based on some doubtful allegations, this is not something we're content with (Организация Объединенных Наций, 2019). В приведенном примере конфликтема основана на использовании двух синонимичных пейоративов: «голословное обвинение» и «подложное дело». Здесь мы наблюдаем комбинирование разноуровневых средств отрицательной оценки: лексических средств (слова с отрицательным коннотативным значением) и грамматических (синтаксических) средств (использование параллельных структур), что увеличивает «степень негативности» оценки, усиливает ее агрессивность. При переводе на английский язык грамматическое средство создания негативной оценки не было использовано. К тому же английское прилагательное “doubtful” по своей семантике не обладает такой же степенью «отрицательности», как передаваемые им русскоязычные прилагательные «голословный» и «подложный». Таким образом, негативная оценка в тексте перевода становится «полуоткрытой», менее эксплицитно выраженной, что, в свою очередь, сглаживает конфликтность высказывания.

Чаще всего, однако, при переводе конфликтемы передавались в полном объеме с сохранением негативной оценочности посредством следующих переводческих приемов:

Модуляция (смысловое развитие): Понятно, что подобные инсинуации - это полнейшие фикции (Прессподход Сергея Лаврова..., 2019). / It is clear that such insinuations are absolutely fake (Россия 24, 2019).

Калькирование, опущение: Низко, подло и недостойно мужчины, я так скажу (Пресс-подход Сергея Лаврова..., 2019). / This is low and unworthy of a man (Россия 24, 2019).

Калькирование: Mr. President, уоu tweeted this morning that it's U.S. foolishness, stupidity, and the Mueller probe that is responsible for the decline in U.S. relations with Russia (President Trump..., 2019). / Господин президент, Вы сегодня написали в Twitter, что эта глупость, тупость США и Мюллер отвечает за спад в отношениях с Россией, между США и Россией (РИА Новости, 2018). 
Прямой перевод (словарное соответствие): ...it was a disgrace to the FBI, it was a disgrace to our country, and, you would say, that was a total witch hunt (President Trump..., 2019). / ...это просто позор для ФБР был. Это фактически позор для нашей страны. И мы должны сказать, что это фактически была охота на ведьм (РИА Новости, 2018).

Как видно из приведенных примеров, негативная оценка не была нейтрализована и ее эксплицитность была сохранена (т.е. эксплицитная негативная оценка не была заменена имплицитной) при переводе, что сохраняет конфликтность высказываний. Здесь следует подчеркнуть, что все конфликтемы на базе негативной оценочности, выделенные нами в исследуемом материале, основывались чаще всего именно на эксплицитной оценке. Данный факт можно объяснить особенностью материала исследования - политической коммуникацией, где важно не только передать конкретную информацию, но и выразить отношение к теме обсуждения, четко обозначить свою позицию в определенном вопросе. Это означает, что конфликт зачастую выступает инструментом достижения определенных целей, что не было бы возможным при использовании неявной, имплицитной оценки.

Языковой фонд средств, выражающих негативную оценку, разнообразен и формируется широким диапазоном разноуровневых языковых единиц: лексическими, грамматическими, просодическими, стилистическими средствами. В исследуемом нами материале большую группу конфликтем на основе негативной оценки представляет пейоративная лексика: разрушительные действия - destructive actions, возмутительная выходка - outrageous incident, паранойя - paranoia, конфронтация - confrontation, напряженность - tension, скандал - scandal, провокация - provocation, блокировать усилия - to block efforts и т.д.

Следует, однако, отметить, что сама по себе пейоративно окрашенная лексика автоматически не выступает в роли конфликтем. Поскольку не все высказывания, содержащие негативную оценку, будут являться конфликтемами. Например: Понятно, что наши отношения с Соединенными Штатами переживают далеко не лучшие времена... / It is clear that our relations have seen better times... (Заявление МИД..., 2020). Коммуникативная интенция данных высказываний - утверждение, констатация факта. Применяя дефиницию конфликтемы Т. Н. Ивановой, приведенную выше, отметим, что у этих лексем отсутствует векторность, т.е. направленность на примирение или наступление в конфликте.

В таком случае особую роль играет лингвистический и экстралингвистический контекст как средство формирования конфликтной ситуации. Рассмотрим следующий пример.

Разумеется, я затронул возмутительную ситуацию с фактическим отказом выдать визы значительной части членов российской делегации - 13 человек, если брать в целом. Как и в день прилета, я еще раз подтвердил, что у меня нет ни малейшего сомнения в том, что ни Президент США Д. Трамп, ни Госсекретарь М. Помпео не имеют к этому никакого отношения - это мне подтвердил М. Помпео. Но если это так, то возникает вопрос, как же там принимаются решения, которые напрямую связаны с выполнением обязательств Вашингтона по обеспечению нормального функционирования итаб-квартиры ООН. И второе соображение в этой связи: когда происходят подобные эксцессы, то исполнители, которые их допускают, видимо, принимают решения, трактуя по своему разумению общую атмосферу в отношениях. Но уж эта-то атмосфера, конечно, создается американским политическим классом. Ежедневно, чуть ли не ежечасно, - то новые санкции, то обвинения России во все новых смертных грехах. Сегодня спикер Палаты представителей Н. Пелоси сказала, что за тем инцидентом, который сейчас раздувают вокруг телефонного разговора между президентами США Д. Трампом и Украины В. А. Зеленским, стоит Россия, что она это подстроила. Просто паранойя, по-моему, очевидная для всех (Выступление и ответы..., 2019).

В приведенном примере можно выделить целый комплекс разноуровневых средств выражения негативной оценки: лексические (слова, имеющие пейоративное значение), грамматические (вопросы, параллельные конструкции), стилистические (разговорная лексика).

Лексические средства представлены следующими пейоративами: возмутительная ситуация, эксцессы, санкции, обвинения, грехи, паранойя. К грамматическим (синтаксическим) средствам можно отнести косвенный вопрос в составе сложного предложения с усилительной частицей «как же», выражающей недоумение: Но если это так, то возникает вопрос, как же там принимаются решения, которые напрямую связаны с выполнением обязательств Вашингтона по обеспечению нормального функционирования итабквартиры ООН. Грамматическим средством экспликации негативной оценки в приведенном отрывке также является структура с повторяющимся союзом «то..., то...», создающим параллельную конструкцию ...mо новые санкции, то обвинения России во все новых смертных грехах. Примерами стилистических средств вербализации негативной оценки выступают разговорное неодобрительное «обвинение во всех смертных грехах», глагол «раздувать» в сочетании с существительным «инцидент» в переносном значении, характерном для разговорной лексики, разговорная усилительная частица «уж» (Но уж эта-то атмосфера).

Таким образом, в общей динамике развертывания конфликтной ситуации разноуровневые языковые средства создания негативной оценки могут «накладываться» друг на друга, создавая многомерный комплекс анализируемых явлений. Следовательно, имеет место синкретизм форм выражения оценки. Все эти формы в совокупности в рамках широкого контекста эксплицируют высокую степень «отрицательности», усиливают агрессивность, тем самым вербализуя конфликтную ситуацию, которая прослеживается только при анализе контекста в целом. Обратимся теперь к переводу данного отрывка на английский язык.

I certainly spoke about the outrageous incident with the US refusal to issue visas to a large number of Russian delegates - 13 persons in all. I repeated what I said on the day of my arrival, saying that I do not doubt that neither President Donald Trump, nor Secretary of State Mike Pompeo were in any way involved, and Mr Pompeo confirmed that this is indeed so. In this case, who takes the decisions that are directly concerned with Washington's obligations to ensure 
the normal operations of the UN Headquarters? Another thought that comes to mind when such incidents take place is that those who take such decisions probably do so based on their own understanding of the general atmosphere in bilateral relations. But this atmosphere is definitely being created by the US political class. New sanctions are adopted against Russia, which is demonized almost every day if not every hour. House Speaker Nancy Pelosi has said today regarding the scandal over the telephone conversation between US President Trump and President of Ukraine Zelensky that she thinks Russia "has a hand in this." I believe this is paranoia, very obviously so again (Организация Объединенных Наций..., 2019).

Как можно заметить, не все языковые средства негативной оценки были переданы в тексте перевода (см., например, такие стилистические средства, как глагол «раздувают» или усилительная частица «уж», характерные для разговорного стиля). Русскоязычный глагол «подстроить» (...она [Россия] это подстроила) со значением умышленного устройства втайне чего-либо обычно неприятного передан на английский язык идиомой have a hand in (...Russia "has a hand in this"), в которой отсутствуют компоненты значения 'втайне' и 'чего-либо неприятного'. Тем не менее, сохранена общая оценочность всего высказывания, что обеспечивает передачу конфликтной ситуации и сохранение степени ее интенсивности. Русскоязычный косвенный вопрос (синтаксическое средство создания оценки) передан на английский язык прямым вопросом: In this case, who takes the decisions that are directly concerned with Washington's obligations to ensure the normal operations of the UN Headquarters? В тексте перевода отсутствует параллельная конструкция, созданная в исходном тексте повторяющимся союзом «то..., то...». Однако негативная оценочность всего предложения передана переводчиком при помощи пейоративов demonize (обвинять во всех смертных грехах) и sanctions (санкции), а также фразой almost every day if not every hour (ежедневно, чуть ли не ежечасно), подчеркивающей постоянство/регулярность описываемой ситуации. К примерам передачи пейоративно окрашенной лексики можно также отнести outrageous incident (возмутительная ситуация) и paranoia (паранойя). Таким образом, при переводе на английский язык, как и в языке оригинала, используется комплекс разноуровневых языковых средств негативной оценки, что в целом и передает конфликтную ситуацию.

\section{Заключение}

Подводя итоги в соответствии с поставленными в исследовании задачами, мы пришли к следующим выводам.

- В речевом (или коммуникативном) конфликте субъекты (стороны) конфликта представлены языковыми личностями, а сама конфликтная ситуация обязательно имеет вербальное выражение и развитие. Языковым средством выражения конфликта выступает конфликтема. Конфликтемы реализуются на разных уровнях языка. Неотъемлемым компонентом конфликтогенных языковых единиц является оценочный компонент, а именно отрицательная (негативная) оценка, составляющая основу конфликтем.

- В большинстве случаев переводчики придерживаются стратегии конфронтации, выбранной коммуникантом, и сохраняют конфликтемы, что, на наш взгляд, может объясняться особенностью материала перевода, в частности, политическая коммуникация определяет общую политическую стратегию сторон, что допускает подобное речевое поведение. Такое коммуникативное поведение преследует определенные цели, а конфликт выступает инструментом достижения этих целей. Соответственно, в данном случае переводчик не вправе подменять речевую стратегию участников коммуникации.

- В зависимости от принятой переводчиком стратегии - сотрудничества или, наоборот, конфронтации будут выбираться соответствующие переводческие приемы. Такие приемы перевода, как генерализация и опущение позволяют смягчить негативную оценку и тем самым уменьшить конфликтогенный потенциал конфликтемы. Тогда как калькирование, прямой перевод (словарное соответствие) или модуляция позволяют сохранить оценочную нагрузку всего сообщения с минимальными потерями или вовсе без потерь.

Перспективы проводимого исследования видятся в расширении его материала. Интерес может представлять изучение средств вербализации конфликтной ситуации и их перевода в бизнес-коммуникации (что, однако, может быть осложнено тем, что материалы деловых переговоров, как правило, представляют собой конфиденциальную информацию, которая не выносится в открытый доступ), а также в научной коммуникации. Кроме того, на текущем этапе работы была рассмотрена только одна группа конфликтем из всего существующего многообразия. Включение в анализ остальных групп данного явления также составляет перспективу представленного исследования.

\section{Источники | References}

1. Алексеева И. С. Введение в переводоведение: учеб. пособие для студ. филол. и лингв. фак. высш. учеб. заведений. СПб. - М., 2004.

2. Арнольд И. В. Стилистика. Современный английский язык: учебник для вузов. Изд-е 5-е, испр. и доп. М.: Флинта; Наука, 2002.

3. Виноградова Е. В. Стратегии переводчика в конфликтных ситуациях международного общения // Университетские чтения-2013: материалы науч.-метод. чтений: в 17-ти ч. Пятигорск, 2013. Ч. 1 / отв. ред. З. А. Заврумов. 
4. Выступление и ответы на вопросы СМИ Министра иностранных дел России С. В. Лаврова в ходе прессконференции по итогам недели высокого уровня 74-й сессии Генеральной Ассамблеи ООН, Нью-Йорк, 27 сентября 2019 года. 2019. URL: https://m.rus.rusemb.org.uk/article/vystuplenie-i-otvety-na-voprosy-smiministra-inostrannyh-del-rossii-svlavrova-v-hode-press-konferencii-po-itogam-nedeli-vysokogo-urovna-74-jsessii-generalnoj-assamblei-oon-nu-jork-27-sentabra-2019-goda

5. Жельвис В. И. Поле брани. Сквернословие как социальная проблема в языках и культурах мира. М.: Ладомир, 2001.

6. Заявление МИД России в связи с пятилетием заключения Совместного всеобъемлющего плана действий по урегулированию вокруг иранской ядерной программы (СВПД). 2020. URL: https://www.mid.ru/ru/foreign_ policy/news/1436895/

7. Иванова Т. Н. Конфликтный диалог: логика развития и структурные элементы // Вестник Русской христианской гуманитарной академии. 2012. № 4.

8. Киндеркнехт А. С. Конфликтологическая компетентность переводчика как образовательная возможность // Индустрия перевода: материалы XI Междунар. науч. конф. (г. Пермь, 13-15 июня 2019 г.). Пермь, 2019.

9. Миньяр-Белоручев Р. К. О функциях переводчика // Информационно-коммуникативные аспекты перевода / под ред. С. А. Семко. Горький, 1986.

10. Нелюбин Л. Л. Толковый переводоведческий словарь. Изд-е 3-е, перераб. М.: Флинта; Наука, 2003.

11. Организация Объединенных Наций. Sergey Lavrov (Russia) - Press Conference (27 September 2019) [видео]. 2019. URL: https://youtu.be/O-FMcVyMX_4

12. Осипова А. А. Конфликтемы в речевом взаимодействии // Magister Dixit. 2011. № 4.

13. Пресс-подход Сергея Лаврова и Майка Помпео по итогам переговоров [видео]. 2019. URL: https://youtu.be/ $189 \mathrm{CmzhKy}-\mathrm{s}$

14. РИА Новости. Пресс-конференция Путина и Трампа [видео]. 2018. URL: https://youtu.be/-tRFqfeOKKw

15. Россия 24. Пресс-конференция Сергея Лаврова и Майка Помпео по итогам переговоров [видео]. 2019. URL: https://youtu.be/ybsP5cdpdCs

16. Третьякова В. С. Конфликт глазами лингвиста // Юрислингвистика. 2000. № 2.

17. President Trump Holds a Joint Press Conference with the President of the Russian Federation [видео]. 2019. URL: https://youtu.be/ujCa6QZCirU

\section{Информация об авторах | Author information}

RU Дедюхина Анна Сергеевна ${ }^{1}$, к. филол. н.

Иванова Светлана Анатольевна ${ }^{2}$, к. филол. н., доц.

Шагеева Анна Алексеевна ${ }^{3}$, к. филол. н., доц.

1, 2, 3 Уральский федеральный университет имени первого Президента России Б. Н. Ельцина,

г. Екатеринбург

EN Dediukhina Anna Sergeevna ${ }^{1}, \mathrm{PhD}$

Ivanova Svetlana Anatolievna ${ }^{2}, \mathrm{PhD}$

Shageeva Anna Alexeevna ${ }^{3}, \mathrm{PhD}$

${ }^{1,2,3}$ Ural Federal University named after the first President of Russia B. N. Yeltsin, Yekaterinburg

${ }^{1}$ a.s.dediukhina@urfu.ru, ${ }^{2}$ s.a.ivanova@urfu.ru, ${ }^{3}$ a.a.shageeva@urfu.ru

\section{Информация о статье | About this article}

Дата поступления рукописи (received): 28.11.2021; опубликовано (published): 28.02.2022.

Ключевые слова (keywords): конфликтема; коммуникативная интенция высказывания; оценочность; передача конфликтной ситуации при переводе; переводческая стратегия; conflictogenic word; communicative intent; evaluative connotation; conflict situation in translation and interpreting; translation strategy. 